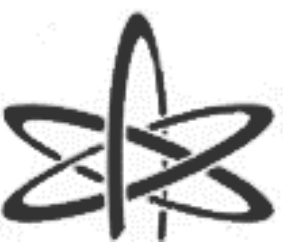

BJRS
BRAZILIAN JOURNAL

$\mathrm{OF}$

RADIATION SCIENCES

06-02-B (2018) 01-16

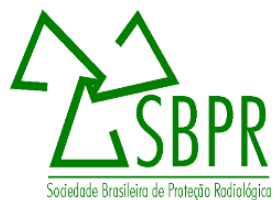

\title{
Knowledge management in radiation protection: The Goiânia accident - learning in the face of tragedy
}

\author{
Silva ${ }^{\mathrm{a}}$ L.C.J., Razuck ${ }^{\mathrm{a}}$ F.B. \\ ${ }^{a}$ Instituto de Radioproteção e Dosimetria (IRD)/Comissão Nacional de Energia Nuclear (CNEN)/Serviço de Ensino \\ (SEENS), 22780160, Rio de Janeiro, Brasil
}

fernandor@ird.gov.br

\begin{abstract}
A radiological accident usually ends up bringing damage to society. The Goiânia accident, which turned 30 in 2017, is no different. However, the term accident, which usually refers to damage, can also lead to discussion of social issues, thus generating knowledge. In this context, the objective of this work was to present some contributions of learning in the radiation protection area from this accident. In this case, a thematic activity was held, together with the students of the Specialization Course in Radiological Protection and Security of Radioactive Sources, offered jointly by the Institute of Radiation Protection and Dosimetry (IRD) and the International Atomic Energy Agency (IAEA). The study focused on the performance of the IRD during the accident. A number of current IRD professors from the Specialization course were involved in responding to the accident made statements about what was the greatest legacy of the accident for the radiation protection area and the students discussed the importance of the Goiânia event. Thus, it was sought to evidence the radiological accident as a learning tool in the field of nuclear science, opening space for discussions in a wider field of knowledge relating to ionizing radiation. In this way, it is impossible to deny the technological advancements or the learning that originated from this tragedy on Brazilian soil, understanding that the investigations related to historical events end up leading to enhancements in the study of radiation protection.
\end{abstract}

Keywords: Accident of Goiânia, Knowledge Management, Radiation Protection. 


\section{INTRODUCTION}

\subsection{The Goiânia accident and the importance of knowledge management}

A radiological accident usually ends up causing damage to society, either to people or to the environment. Given this context, the Goiânia accident, which turned 30 in 2017, is no different. However, the term accident, which usually refers to damage, can also lead to discussion of social issues, thus generating knowledge.

An accident can be considered an unintentional event, including operational errors and equipment failures, whose actual or potential consequences are relevant. From the point of view of radiation protection, nuclear accidents are those occurring in facilities such as nuclear reactors and nuclear fuel cycle facilities. On the other hand, radiological accidents can also involve sources of ionizing radiation used in various practices and can occur anywhere [1].

In the case, the Goiânia accident also known as the "Cesium-137" accident is currently considered the largest radiological accident in the world, placing Brazil in the list of countries involved in a tragic radiological accident [2].

The accident happened due to the uncontrolled release of highly radioactive Cesium-137 (with activity of $50.9 \mathrm{TBq}$ - or $1375 \mathrm{Ci}$ ), which was discharged into the environment, causing the contamination of several locations. The accident occurred due to a series of errors, such as the abandonment of an irradiator used in the radiotherapy service of a local hospital that contained a capsule of Cesium-137 chloride and due to the lack of information of the local residents - the capsule was passed on to several other individuals, exposing more than one thousand individuals and generating a trail of contamination that affected 129 people. Of these, 49 were hospitalized with severe symptoms and, after intensive treatment, 4 did not respond to treatment and eventually died [1].

Furthermore, it took 15 days for Brazil's National Commission of Nuclear Energy (CNEN), to be informed about the incident, who in turn notified the International Atomic Energy Agency 
(IAEA). An emergency plan was then launched, with the participation of CNEN and various institutions, including the Institute of Radiation Protection and Dosimetry (IRD) [1].

The Goiânia accident is considered by the IAEA as the worst event with radioactive sources, and is responsible the IAEA implementing a regular publishing cycle detailing descriptions of all accidents and the lessons identified within the most recent period. It is classified in the International Scale of Nuclear and Radiological Accidents (INES) as level 5, being the only radiological accident outside nuclear installations with this classification [3].

According to CNEN standard 3.01, for example, radiation protection is a set of measures designed to protect humans, their offspring and the environment against possible undue effects caused by ionizing radiation from sources and technologically modified natural sources [4].

When approaching learning in the face of tragedy, through the radiological accident in Goiânia, one cannot fail to emphasize the importance of Knowledge Management as a tool both for the training of human resources, but also in the legacies left from events of this nature.

So,

The management of information and knowledge is a theme that has been widely discussed, in several spaces, in Brazil, especially in higher education organizations and institutions. This is a complex discussion that involves many aspects both because it is located at points of intersection between several fields of knowledge, notably Administration, Computer Science and Production Engineering, as well as the objective constraints of its organizational theories and practices. [5, p. 55].

Thus, Knowledge Management as a discipline started with Information Science and has since expanded to all other areas [6]. It can be inferred that:

The understanding of Knowledge Management according to the process by which strategic information is identified, analysed and interpreted with the purpose of generating new information and knowledge that support the processes of decision-making and action demonstrates that this process can be applied in other environments other than business. Information flows are established by all human activities and Knowledge Management can be applied, according to the purpose of each enterprise, whether scientific, business or political [7, p. 15].

Therefore, one example is Nuclear Knowledge Management, linking the energetic institutions nominated in this paper - CNEN, IRD and the IAEA, as will now be demonstrated. 


\subsection{The CNEN, the IRD and the IAEA}

In view of the importance of the institutions related to the issue of radiation protection, this paper will now present briefly their structures and functions. CNEN is a federal authority associated to the Ministry of Science, Technology, Innovations and Communications (MCTIC), created in 1956 and structured by Law 4.118, on August 27, 1962, to develop the national nuclear energy policy. The CNEN establishes rules and regulations in radiation protection and is responsible for regulating, licensing and supervising the production and use of nuclear energy in Brazil. CNEN also invests in research and development, seeking an increasingly broad and secure use of techniques in the nuclear sector, its focus is to guarantee the benefits of nuclear applications to an increasing number of Brazilians, always with safety and security as paramount concern [8].

The IRD is a research, development and teaching institution in the field of radiation protection, dosimetry and metrology of ionizing radiation. Connected to CNEN's Directorate of Radiation protection and Nuclear Safety (DRS), it works in collaboration with universities, government agencies and industries to promote the safe use of ionizing radiation and nuclear technology. Its activities of research, technical support and service rendering have enabled the development of new technologies and the implementation of solutions for the benefits of the use of ionizing radiation safely reaching an increasing number of Brazilians. IRD’s professionals work to create research, technological development and industrial innovations, medical facilities, research centres and more, in order to contribute to the safety of the population, workers in the sector and the environment [9].

The IAEA is an autonomous international organization with direct relations to the United Nations (UN). It was created on July 29, 1957 and is headquartered in the city of Vienna. Initially, the IAEA emerged from the "Atoms for Peace" project, presented to the United Nations General Assembly in 1953 by the then President of the United States. The IAEA's relationship with the UN is regulated by a special agreement and, according to its own statute, the agency submits an annual report to the United Nations General Assembly [10].

The three main pillars of the IAEA's performance are: safety and security, science and technology and safeguards, of these its primary objective is for the safe and peaceful use of atomic energy. Its main objectives are: to promote the peaceful and safe use of atomic energy throughout the world; inhibit the use of atomic energy for military purposes, such as the manufacture of atomic 
bombs; assist member countries in improving scientific and technological capabilities in the peaceful applications of atomic energy; to promote among member countries the use of nuclear techniques for sustainable development and development of programs aimed at the safety and protection of people and the environment against the harmful effects of nuclear radiation. Therefore, in general, the IAEA's mission is guided by the interests and needs of the member states, the strategic plans and the principles of the organization's statute [10].

\section{MATERIALS AND METHODS}

After the Goiânia accident, in 1987, it was questioned how its story could contribute to the study of radiation protection? Trying to answer this question, and considering the relevance of the accident to the learning of radiation protection, a thematic activity was held with the students of a Specialization course in Radiological Protection and Security of Radioactive Sources, focusing on the performance of the IRD during the accident.

The Postgraduate Educational Course (PGEC) in Radiological Protection and Safety of Radiation Sources has been offered since 2011 by the IRD in partnership with the IAEA and was designed to meet the needs of professionals with higher education at university level and working in the field of radiation protection and radiation source safety. The course design is structured to provide theoretical and practical training, whether scientific and/or technical, based on international recommendations and standards on radiological protection and its implementations. The course provides the basic tools needed for those who will become instructors in radiation protection area (Qualified Experts) [11].

Divided into modules, it includes theoretical studies and practical training, with demonstrations, laboratory exercises, case studies, technical visits, simulation exercises and workshops. The course takes into account the requirements of the International Basic Safety Standards for Protection against Radiation Sources (BSS), "IAEA Safety Series No. 115 (1996)" and the related safety recommendations in "Safety Guides" [11]. 
Thus, this work aimed to make a historical survey of the importance of the IRD's actions during the Goiânia accident, in order to approach Knowledge Management in the area of radiation protection, based on the lessons learned during the accident.

A qualitative and quantitative research was adopted in this study [12]. To this end, three professors of the course, who acted in the emergency during the Goiânia accident, made statements about the greatest legacies or lessons learned for the radiation protection area. The interviews were individual and centred around three questions: a) briefly describe the accident; b) what were your actions and activities during the accident; and c) what was the greatest legacy of the accident to radiation protection area.

From the analysis of the interviews, and the observations made in the classroom during the course, the main points were highlighted and a bibliographical review on the subject was carried out.

After this, a discussion was held with the students about the relevance of the accident, with emphasis on radiation protection. Finally, a questionnaire was completed with the class involving questions about the accident, based on the classes, bibliographical review and the testimonies, in order to make a quantitative and qualitative survey of student's views.

\section{RESULTS AND DISCUSSION}

Now, the results will be presented in relation to the teachers interviewed, the questionnaire applied to the students, the bibliographical review and the discussion about the main legacies for the radiation protection area highlighted during the discussion among the students during the thematic workshop.

\subsection{Bibliographical review}

Through student's research, it was possible to find a series of articles, books, movies and videos about the accident. For example, a publication by the IAEA [1], which provided a description of the Goiânia accident with observations and recommendations. Among these, it cited the emergency planning belonging to CNEN at the time of the accident, since the CNEN Emergency Plan was 
designed to deal with two main categories of accidents: first, it was designed to manage a radiological accident at the nuclear power plant in Angra dos Reis (Rio de Janeiro); and secondly, there were protocols to deal with radiological emergencies in the non-nuclear energy sector.

Generally, these types of accidents are expected on a small scale; for example, transport accidents or radiographic accidents. The Goiânia accident did not fall into any of these categories, and elements of the two sets of emergency arrangements had to be readjusted and applied.

So, of the various lessons learned in this accident, one can refer to the one that deals with responsibility in knowing the consequences of dealing with science and technology, to extend the care that prioritizes ethics and respect for life [13].

In 2008, in its annual report, the IAEA expressed concern about a possible shortage of people with expertise in the nuclear sector. It then published the Planning and Implementation Guidance document on Knowledge Management, which emphasizes that, in the immediate future, science education and technology should be treated as a priority, that is, transfer and capture the knowledge of current generations in an agile way [14].

\subsection{Teacher Interviews and Observations During the Course Classes}

Interviews were conducted with professors of the course, in which they pondered what the greatest legacies (lessons learned) were left by the Goiânia accident for the radiation protection area. Below are the transcribed interviews:

Professor A: The accident in Goiânia surprised the Brazilian society, including CNEN, the radiological regulator. The accident was marked by exhaustive work for those involved. Brazil had never had a similar situation, a lot of incomplete information was received by authorities, in part because in the week of the accident, there was a motorcycle championship in Goiânia and many tourists were present in the city, in a way with the presence of many people, the case took time to reach the public awareness. Before the radiological accident in Goiânia, there was already an emergency group in the CNEN (in the IRD), in which I was a member, but this group was not prepared for accidents of that magnitude, but for nuclear accidents and specifically in nuclear plants. Some relevant factors can be enumerated as: communication, equipment, specialized laboratory, tailings generation and training. Communication was not a collaborative tool, because information was not shared at all levels, in a clear way, i.e. because of lack of knowledge, by journalists on ionizing radiation, each reported what they thought was right and convenient, and this in a way caused even more panic for the population. The equipment used at the time, for the detection of radiation, produced by different manufacturers, caused some confusion due to their different radiation scales. It would have been beneficial to have setup a temporary laboratory in Goiânia, to assist in the measurements and calibration of the equipment, this 
would provide the quickest answers and optimize all tracking and monitoring. Another point worth mentioning was the segregation of people, there was not an appropriate place for the injured people to stay, Goiás state government, provided a football stadium for the injuried persons to stay, this location provided people with hot meals and their physiological needs.

Professor B: Before the date of the accident, there was already an emergency group, but it was only for nuclear emergencies, the only thing the military was afraid of was an accident at the nuclear power plant, that is, all our emergency preparedness was aimed at a nuclear accident and the emergency plans were modeled on the Three Mile Island nuclear accident. Another point that was relevant in this work was the relationship of the technicians with the press, it is one thing to talk to a technician in the radiological area about equivalent dose in terms of unit and another thing is to speak to the press and say that there are $3 \mathrm{mRem}$, $4 \mathrm{mRem}$ the source had so many thousand curie or becquerel the journalist has no idea what you are talking about, so he will put whatever he wants in his report, it happened so often the technician who was working there was interviewed. Radio, television and newspaper reporters conveyed incorrect information. At that time there was no internet, and when the population asked a technician about what was happening he would answer about mRem, while the journalist wrote a thousand rem or something similar. This, in general, caused more panic than helped. As a lesson learned, today the IRD has a public relations representative who is there to ensure correct communication between the technician and the press. After our experience there has been large changes in the approach for nuclear emergencies, now we are better prepared for any kind of radiological or nuclear emergency. The new strategy in the event of nuclear incident changed so that the military have control and command of the operations with expert support and advice from CNEN and additional support from other public services e.g. Civil Defense, and the Fire Brigades. Now at IRD, there are courses in the area of radiation protection and emergency.

Professor C: I consider this as one of the most severe radiological accidents, which was responsible for the contamination of hundreds of people and many places spreading throughout not just the city of Goiânia but also the State of Goiás. The accident with Cs 137 brought some lessons that, after thirty years, can be highlighted. As the authorities of the country were surprised and the population of Goiânia was terrified, the action of the IRD technicians, at the beginning, was restricted to the isolation of the primary outbreak locations and in the identification of the contaminated people, with help from the Local Health Surveillance. This was completed by IRD technicians, together with other CNEN professionals, even without adequate infrastructure. The team lead the management of all the processes: taking care of the victims and identification of emergency evacuations for victims in more serious situations to the Rio de Janeiro, public screening, isolation of affected areas, decontamination and remediation of residues and contaminated objects, segregation and transportation of tailings generated, design and construction of temporary repository, preparation of official statements including interviews and daily contacts with the means of communication. All this in order to help the population return to a feeling of peace and normality. As can be seen, all the work in the critical areas was conducted with a great deal of emphasis on safety and radiation protection, both by the CNEN technicians themselves and by the staff of other institutions that participated as auxiliaries in the work of decontamination of people and recovery of areas. 


\subsection{The thematic activity with the students}

A questionnaire was given to verify the students' vision regarding the events that occurred during the radiological Goiânia accident, starting from the classes, reading the interviews, discussing in the classroom and bibliographical research. The questions, the percentage of correct and incorrect answers, and some examples of student responses are shown in Table 1 below.

Table 1: Questionnaire applied to students about their knowledge on the Radiological Goiânia accident.

\begin{tabular}{|c|c|c|c|}
\hline QUESTIONS & \% CORRECT & \% INCORRECT & EXAMPLE \\
\hline \multirow[t]{2}{*}{$\begin{array}{l}\text { 1) What is the } \\
\text { difference } \\
\text { between } \\
\text { nuclear, } \\
\text { radioactive and } \\
\text { radiological } \\
\text { accident? }\end{array}$} & \multirow[t]{2}{*}{86} & \multirow[t]{2}{*}{14} & $\begin{array}{l}\text { Correct - "Nuclear accident } \\
\text { involves nuclear reactors and } \\
\text { their fuel. Radiological accident } \\
\text { involves radioactive sources or } \\
\text { radiation generating and } \\
\text { radioactive accident is the same } \\
\text { as radiological accident." }\end{array}$ \\
\hline & & & $\begin{array}{l}\text { Incorrect - Student did not know } \\
\text { how to respond. }\end{array}$ \\
\hline \multirow{2}{*}{$\begin{array}{l}\text { 2) Do you know } \\
\text { of any nuclear, } \\
\text { radioactive or } \\
\text { radiological } \\
\text { accidents? } \\
\text { Name them. }\end{array}$} & \multirow[t]{2}{*}{93} & \multirow[t]{2}{*}{7} & $\begin{array}{l}\text { Correct - "Goiânia Accident, } \\
\text { Fukushima Chernobyl and Three } \\
\text { Mile Island.". }\end{array}$ \\
\hline & & & $\begin{array}{l}\text { Incorrect - student did not } \\
\text { respond. }\end{array}$ \\
\hline $\begin{array}{l}\text { 3) In your } \\
\text { opinion, what } \\
\text { precautionary } \\
\text { measures } \\
\text { should be } \\
\text { adopted to } \\
\text { prevent further } \\
\text { accidents of this } \\
\text { nature? }\end{array}$ & 100 & 0 & $\begin{array}{l}\text { Correct - "Intensify compliance } \\
\text { with radiological protection } \\
\text { measures and physical } \\
\text { protection of sources and } \\
\text { facilities". }\end{array}$ \\
\hline
\end{tabular}




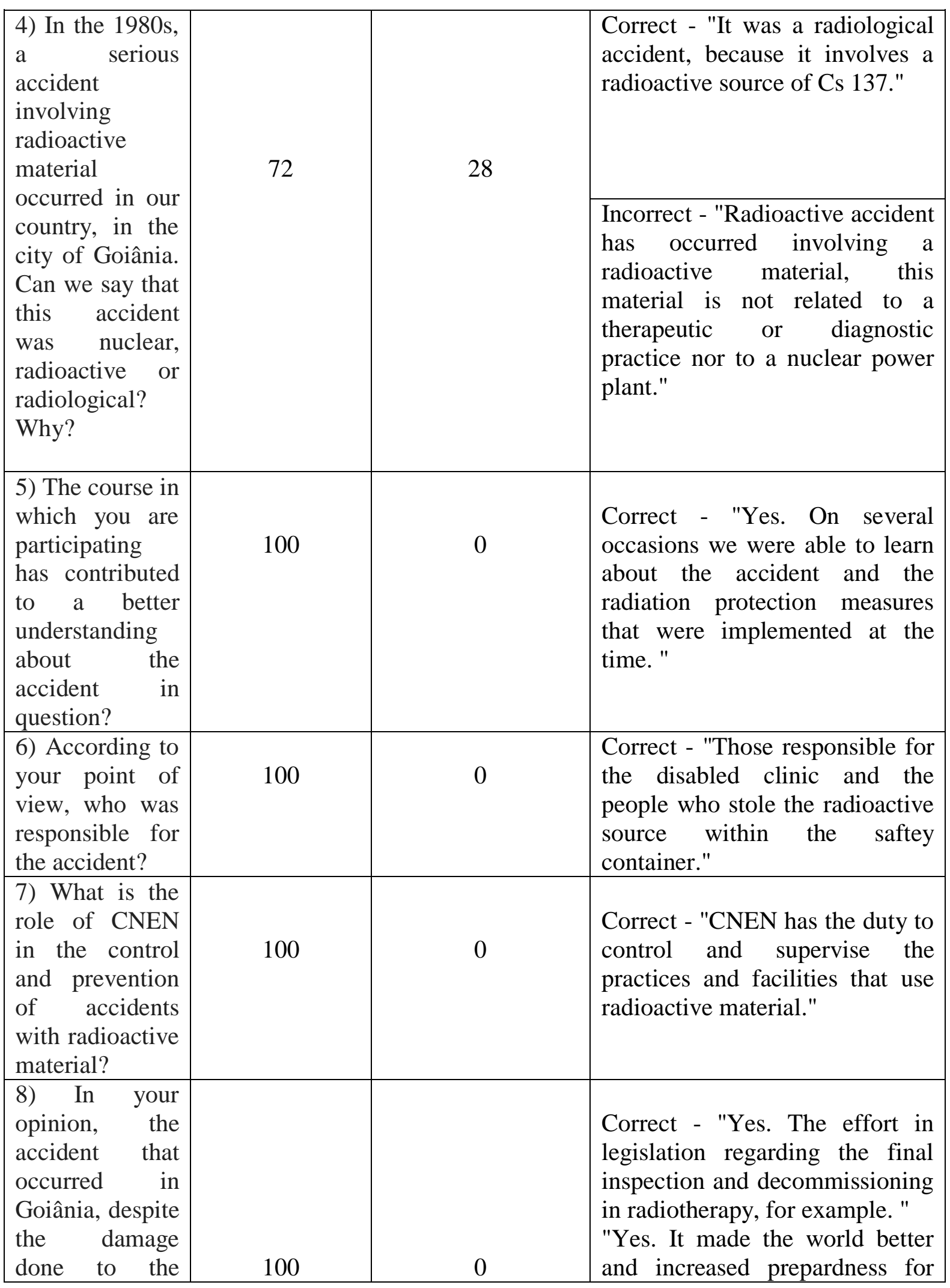




\begin{tabular}{|c|c|c|c|}
\hline $\begin{array}{l}\text { victims, left } \\
\text { some legacy or } \\
\text { learning in the } \\
\text { area of } \\
\text { radiation } \\
\text { protection? } \\
\text { Which are } \\
\text { they? }\end{array}$ & & & $\begin{array}{l}\text { another radioactive emergency, } \\
\text { thanks to Goiânia accident." } \\
\text { "It was possible to administer } \\
\text { Prussian Blue so that the doses } \\
\text { were delivered in the right } \\
\text { doses." }\end{array}$ \\
\hline \multirow[t]{2}{*}{$\begin{array}{l}\text { 9) What is your } \\
\text { opinion about } \\
\text { "Safety } \\
\text { Culture" and } \\
\text { "Knowledge } \\
\text { Management"? }\end{array}$} & \multirow[t]{2}{*}{86} & \multirow[t]{2}{*}{14} & $\begin{array}{l}\text { Correct - "Safety Culture: aims } \\
\text { to minimize or prevent the } \\
\text { occurrence of accidents, through } \\
\text { training, compliance with } \\
\text { procedures for use and handling } \\
\text { of equipment, use of PPE, etc.". } \\
\text { "Knowledge Management: } \\
\text { Knowledge must be shared in a } \\
\text { clear, objective and responsible } \\
\text { manner." }\end{array}$ \\
\hline & & & $\begin{array}{l}\text { Incorrect - Student did not } \\
\text { comment on safety culture and } \\
\text { knowledge management. }\end{array}$ \\
\hline $\begin{array}{l}\text { 10) When } \\
\text { talking about a } \\
\text { radiological } \\
\text { accident, we } \\
\text { have to take } \\
\text { into account } \\
\text { relevant } \\
\text { concepts such } \\
\text { as: radiation } \\
\text { protection, } \\
\text { safety culture } \\
\text { and knowledge } \\
\text { management. In } \\
\text { your opinion, } \\
\text { have these } \\
\text { concepts been } \\
\text { addressed in the } \\
\text { course in which } \\
\text { you are }\end{array}$ & 100 & 0 & $\begin{array}{l}\text { Correct - "These concepts have } \\
\text { been covered in the classroom, } \\
\text { especially the concept of } \\
\text { radiation protection has been } \\
\text { systematically addressed in } \\
\text { classroom lessons. Less } \\
\text { frequently, security culture and } \\
\text { knowledge management." }\end{array}$ \\
\hline
\end{tabular}


participating as a student?

After the questionnaire was applied, a debate was held among the students about the accident and the importance of its legacy for the radiation protection area. Regarding the observations made during the course, in general, in each module of the course a legacy was identified in the area. But for the program's teachers, the most important thing was the quick response that the IRD's staff gave in an unfavourable and never-before-experienced scenario. For example, until then, the IRD did not have an accident emergency team prepared for an accident of that magnitude, only for an event related to a nuclear accident. Even so, the IRD promptly responded by sending its professionals who worked day and night on remediation of the accident.

From the analysis of teacher's testimonies and the dynamics of discussion with students about the accident, it can be observed that several actions in radiation protection have evolved since then, mainly in the following areas:

- Medical Physics - such as the treatment of "Prussian Blue" used in accidents and the replacement of Cesium-137 in radiotherapy;

- Radiological Emergency - such as classifying events, communicating with the public, adopting an action plan for radioactive accidents;

- Social Service - such as psychological and social treatment of the victim's families; and

- Human Resource Formation - such as attracting students and Teachers to the area.

Thus, it can be concluded from this work that the greatest lessons learned from the point of view of radiation protection were:

- the health study and the follow-up and treatment of the victims;

- previously restricted to nuclear installations, the accident required the computerization of all processes related to radiation protection and licensing of radioactive facilities; it was necessary to complete this activity across the whole country for the tracking, control and classification of radioactive sources used in different applications; 
- Today, the country has consolidated technical knowledge for the construction of low and medium intensity radioactive waste repositories; and

- The sector linked to the radiation protection of nuclear and radioactive facilities started to count on greater planning, coordination, integration and training between the different federal and state agencies, responsible for civil defence, surveillance and security control of equipment and sources in relation to nuclear and radiological services and emergencies;

Finally, specifically on emergency procedures, some key practices were identified, such as:

- establish a chain of command that must be clearly identified (hierarchy);

- the existence of a permanent national program of inspections of equipment and installations using radioactive materials is essential;

- the consequences of a radiological accident are directly proportional to the time interval between the beginning of the accident and its effective identification and communication;

- knowledge of the physical and chemical properties of the radioactive source are very important factors in guiding response actions; an adequate information system is essential for controlling panic rumours;

- an adequate psychological and social support system is essential to deal with individuals directly and / or indirectly affected by the accident, be they members of the public or emergency workers; each country must be adequately prepared to receive international assistance;

- courses and training in response to radiological emergency situations should be conducted for all responders;

- measurement instruments must be robust enough to withstand adverse environmental conditions;

- a database containing information on experts in the various areas of knowledge required for emergency response should be maintained;

- the prompt definition of a location, close to the area affected by the accident, is essential for the temporary storage of radioactive waste generated; and

- Logistic support teams should make up response teams (engineering, supplies, transportation, etc.). 


\section{CONCLUSION}

Thirty years after the tragic accident with Cesium 137, it is necessary to discuss possible contributions in the area of radiological sciences, educating more qualified professionals for the development of their activities, with solid knowledge in radiation protection, considering lessons learned from past accidents.

Thus, it is necessary to observe that in the face of tragedy, lessons can also be learned, which will serve as guiding tools so that events of this nature will not happen again - and if they occur again, there will be a coordinated action of the responsible emergency teams. Therefore, the tragedy of the Goiânia accident cannot be forgotten, since preserving the past, telling its story, is a way to avoid new mistakes.

As previously mentioned, it is important to highlight the radiological accident as a tool of Knowledge Management in the field of nuclear science, opening space for a wider learning about ionizing radiations. In this way, this work was carried out with the objective of identifying which were the greatest legacies for the area of radiation protection. In this sense, through Knowledge Management, it is understood the importance of this knowledge to the one of radiation protection.

Consequently, it is necessary to establish methods for the discussion and understanding of information and knowledge management. In this case, the activity tried to verify with the students the knowledge and information they had about the accident and how this fact impacted on their academic lives. This methodology allowed us to qualitatively measure the influence and impact of this tragic accident.

Regarding the dissemination of knowledge, the IRD has been playing a relevant role in the training and qualification of professionals in radiation protection, seeking practices that stimulate the production and sharing of new knowledge. Therefore, it can be concluded that the IRD is a multiplier institution of nuclear knowledge. This work was carried out with the objective of identifying which were the greatest legacies for the area of radiation protection. 


\section{REFERENCES}

[1] IAEA. International Atomic Energy Agency. The radiological accident in Goiânia. Vienna, 1988.

[2] FALEIROS, A. Uma História para Relembrar e Prevenir. Revista Césio 25 anos. 2012.

[3] ENERGIA NUCLEAR. Acidentes Nucleares. Available at:< https://pt.energianuclear.net/acidentes-nucleares>. Last Accessed: 07 de mai. 2017.

[4] OKUNO, E. Efeitos biológicos das radiações ionizantes. Acidente radiológico de Goiânia. Estudos Avançados, 27 (77), 2013.

[5] SOUZA, E. D.; DIAS, E. J. W.; NASSIF, M. E. A gestão da informação e do conhecimento na ciência da informação: perspectivas teóricas e práticas organizacionais. Inf. \& Soc.: Est., João Pessoa, v.21, n.1, p. 55-70, jan./abr. 2011.

[6] BITTENCOURT, M.; R. de B. CIANCONI. Produção e Compartilhamento do Conhecimento Nuclear: Um estudo de caso no Instituto de Engenharia Nuclear da Comissão de Nacional de Energia Nuclear (IEN/CNEN). Perspectivas em Gestão \& Conhecimento, João Pessoa, v. 2, Número Especial, p. 175-187, 2012.

[7] SANTOS, C. R. O Gestor Educacional de uma Escola em Mudanças. 1 ed. São Paulo: Pioneira, 2002.

[8] CNEN - Comissão Nacional de Energia Nuclear. Quem somos. Available at:<http://www.cnen.gov.br>. Last Accessed: 12 de abr. 2017.

[9] IRD - Instituto de Radioproteção e Dosimetria. O IRD. Available at:< http://www.ird.gov.br/index.php/o-ird>. Last Accessed: 12 de abr. 2017.

[10] IAEA. International Atomic Energy Agency. Annual report. Vienna, 2013.

[11] IRD. Pós-graduação $\quad$ Lato $\quad$ Sensu. Available at:<http://moodle.ird.gov.br/ensino/index.php/especializacao>. Last Accessed: 07 de mai. 2017.

[12] GIL, A. C. Métodos e Técnicas de Pesquisa Social. 6. ed. - São Paulo : Atlas, 2009. 
[13] CURADO, M. P.; SILVA, D. Histórico do Acidente Radioativo de Goiânia. Goiânia: FunLeide, 1989.

[14] IAEA. International Atomic Energy Agency. Planning and Execution of Knowledge Management Assist Missions for Nuclear Organizations. Vienna, 1988. 